\title{
Learner reflections on a postgraduate emergency medicine simulation curriculum: a qualitative exploration based on focus group interviews
}

\author{
Nicole Kester-Greene ${ }^{1} \cdot$ Caroline Filipowska $^{1} \cdot$ Heather Heipel $^{1} \cdot$ Gerhard Dashi $^{1} \cdot$ Dominique Piquette $^{2}$
}

Received: 10 June 2020 / Accepted: 23 December 2020 / Published online: 6 April 2021

(C) The Author(s), under exclusive licence to Canadian Association of Emergency Physicians (CAEP)/ Association Canadienne de Médecine d'Urgence (ACMU) 2021

\begin{abstract}
Objectives To describe postgraduate emergency medicine (EM) residents' perceptions of simulation-based curriculum immediately post-simulation training.

Methods This interpretive qualitative study explores residents' reflections on a city-wide, adult EM simulation-based curriculum. Focus group interviews gather residents' insights immediately post-simulation. Postgraduate trainees from the University of Toronto EM residency program were eligible to participate. We explored participants' perceptions of how well learning objectives were addressed, helpful/challenging aspects of the simulations, feelings during sessions, debriefing/ pre-briefing, simulation integration into the broader EM curriculum, and anticipated changes in practice after the session.

Results Our findings indicate that EM residents' learning goals for the simulation sessions evolve as they progress through residency training. Junior trainees report performance-oriented goals while senior trainees report learning-oriented goals. Differing motivations may affect residents' perceptions of the quality of the simulation experience. Junior residents want to feel prepared for the scenario and primed with the appropriate knowledge to manage the case. Senior residents focus on developing teamwork competencies and on mastering new clinical skills in the simulation environment.

Conclusions Junior and senior emergency medicine residents differ in their goal orientation during simulation-based training. Educators who develop simulation-based curricula should be mindful that junior residents may benefit from preparatory materials while senior residents prefer to be challenged. Resident reflections may significantly contribute to improvement of simulation-based curricula.
\end{abstract}

Keywords Education simulation $\cdot$ Emergency medicine $\cdot$ Residents and fellows

\section{Résumé}

Objectif Décrire la perception du programme de formation par simulation des résidents en médecine d'urgence (MU) immédiatement après un entraînement par simulation.

Méthodes Cette étude qualitative interprétative explore les réflexions des résidents au sujet d'un programme axé sur la simulation en MU pour adultes à travers la ville. Les entretiens des groupes de discussion recueillent les aperçus des résidents immédiatement après la simulation. Les stagiaires de troisième cycle du programme de résidence en MU de l'Université de Toronto étaient admissibles à participer. Nous avons examiné les perceptions des participants sur la manière dont les objectifs d'apprentissage étaient abordés, les aspects utiles / exigeants des simulations, les sentiments pendant les sessions, le

Nicole Kester-Greene

nicole.kestergreene@sunnybrook.ca

1 Division of Emergency Medicine, Department of Emergency

Services, Sunnybrook Health Sciences Centre, University of Toronto, 2475 Bayview Ave, Toronto, ON M4N 3M5, Canada

2 Interdepartmental Division of Critical Care, Sunnybrook Health Sciences Centre, University of Toronto, Toronto, ON, Canada 
débriefing / pré-briefing, l'intégration de la simulation dans le programme plus large de la MU et les changements anticipés dans la pratique après la session.

Résultats Nos résultats indiquent que les objectifs d'apprentissage des résidents en MU pour les séances de simulation évoluent au fur et à mesure qu'ils progressent dans la formation en résidence. Les stagiaires juniors rapportent des objectifs axés sur la performance tandis que les stagiaires avec plus d'ancienneté rapportent des objectifs axés sur l'apprentissage. Des motivations différentes peuvent affecter la perception qu'ont les résidents de la qualité de l'expérience de simulation. Les résidents assistants veulent se sentir préparés pour le scénario et équipés des connaissances appropriées pour gérer le cas. Les résidents avec plus d'ancienneté se concentrent sur le développement des compétences de travail d'équipe et sur la maitrise de nouvelles compétences cliniques dans l'environnement de simulation.

Conclusions Les résidents assistants et ceux avec plus d'ancienneté en médecine d'urgence diffèrent dans leur orientation vers les objectifs au cours de la formation par simulation. Les éducateurs qui développent des programmes axés sur la simulation doivent être conscients que les résidents assistants peuvent bénéficier des matériels préparatoires tandis que les résidents avec plus d'ancienneté préfèrent être mis au défi. Les réflexions des résidents peuvent contribuer de manière significative à l'amélioration des programmes axés sur la simulation.

\section{Clinician's capsule}

\section{What is known about the topic?}

Current literature provides limited exploration of learners' perceptions of simulation-based curricula and how learner's perceptions may contribute to its refinement.

\section{What did this study ask?}

What are emergency medicine residents' insights on simulation-based training and how does level of training impact their views?

\section{What did this study find?}

Junior and senior emergency medicine residents' differing goal orientation during simulation-based training affects their perceptions of the quality of learning.

\section{Why does this study matter to clinicians?}

Educators who develop simulation-based curricula should be mindful of the differences in goal-orientation amongst junior and senior residents.

\section{Introduction}

Emergency medicine (EM) simulation curricula are traditionally based on program training objectives [1]. Educators construct a simulation experience aligned with objectives which are amenable to simulation-based training. Learners are usually minimally involved in this process; opportunities for learner input is limited after implementation, often through satisfaction surveys or infrequent formal curriculum evaluations. To our knowledge, traditional post-simulation feedback focuses on assessing instructors and evaluating existing curriculum rather than on how well objectives were achieved.
Few studies discuss learners' involvement in simulationbased curriculum improvement. McKendy et al. describe a model wherein surgical residents who developed virtual patient cases viewed their contribution as a valuable educational experience [2]. Mathai et al. describe a simulationbased curriculum delivered by senior medicine residents who had no role in curriculum design [3]. Learners' involvement in simulation curriculum refinement therefore appears to be limited thus far.

Gathering meaningful learner feedback during or after participating in a simulation-based curriculum could optimize alignment between the learners' experience and needs. Simulation, by definition participatory and assumed to be learner-centered, can result in deeper learning as it empowers learners to think for themselves, set their own goals, and learn from educational experiences that have personal meaning [4]. Learners' feedback on their simulation experience could be instrumental in determining how curricular changes can optimize learners' engagement and learning during simulation.

Learning is not limited to scenario participation, but also from debriefing. In one study, senior medical students designed, implemented and debriefed a simulation scenario under faculty supervision [5]. Students spent significant time becoming familiar with debriefing best practices, and were noticed to deliver high-quality debriefing, highlighting the importance of this activity for trainee involvement and learning.

While numerous studies have reported high levels of learner satisfaction after simulation-based training (but exclude learners' reflections on their simulation experience), we found no literature describing how learners' perceptions contributed to simulation curriculum improvement $[6,7]$. We sought to explore EM residents' perceptions of an existing city-wide simulation curriculum immediately after their participation in a bi-monthly simulation session. The 
purpose of this work is to inform EM postgraduate simulation curriculum refinement.

\section{Methods}

We conducted an interpretive qualitative study using grounded theory principles to explore residents' reflections on a city-wide, adult EM simulation-based curriculum [8] The University of Toronto (UofT) EM residency program developed and implemented a simulation-based curriculum over the last 6 years. We used this on-going initiative to better understand how residents can contribute to its improvement. We gathered insights from focus groups of residents immediately after completing a simulation session [9]. We selected focus group interviews as a data collection method to efficiently gather perceptions of a range of learners with the expectation that peer interaction during interviews would generate new insights. Institutional REB approval and written consents were obtained prior to the study conduct.

\section{Participants and setting}

All residents from the UofT FRCP EM residency program were eligible to participate. The 5-year program includes, on average, a total of 50 residents. EM Residents participate in a three-hour bi-monthly session in groups of 4-6 junior (PGY1-2) or senior ( $\geq$ PGY3). trainees. Each session includes 2-3 simulations, with residents taking turns playing the role of the leader. Scenarios differ between junior and senior trainees. Each 15-min simulation is followed by a 30-min debriefing. Sessions are facilitated and debriefed by EM faculty. Scenario development was based on the Royal College EM Objectives of Training [10].

We purposefully selected simulation sessions that included different cases, were held at two different hospital sites, and were debriefed by different facilitators. We hypothesized that training level could affect residents' ability to reflect on their experience, and therefore selected sessions targeting junior (PGY1-2) and senior (PGY3-5) residents, respectively. We planned to conduct 6 focus group interviews (total of 20-25 participants). The initial interview guide was developed by two of the investigators (DP and NKG), reviewed by all co-investigators, and modified throughout data collection based on interviewers' feedback and initial analyses (see Supplementary material for interview guides). Data was collected and analyzed iteratively, and data collection was stopped when theoretical sufficiency was achieved, i.e. when enough data was available to elaborate on each main theme [11].

\section{Conduct of focus group interviews}

EM residents were invited by email to participate in a focus group immediately after the last debriefing of selected simulation sessions. At each session, residents were reminded about the study and asked to provide written consent to participate in the focus group interview. Each interview was facilitated by 1 or 2 interviewers not involved in the simulation design or delivery. The interview guide included questions that explored participants' perceptions regarding learning objectives, helpful and challenging aspects of current and previous simulations, simulation integration into the broader EM curriculum, and anticipated changes in practice (see Supplemental Material). Our intent was also to explore residents' suggested improvements to simulation sessions and curriculum. The interviews were audio-recorded, transcribed verbatim, and anonymized. Interviewers also kept field notes during the interviews.

\section{Data analysis}

We performed an inductive content analysis using the anonymized transcripts and interviewer field notes [12]. As soon as the data collection started, data analysis was initiated. Each transcript was read, re-read, and discussed by the interviewers and investigators (see Supplemental Material for description) to identify interesting lines of inquiry and modify, as needed, the interview guide. During the coding process, themes were identified, defined, and grouped into categories based on constant comparisons between junior and senior participants and between interviews. Once a coding structure was established, the complete dataset was analyzed using this structure. Investigators had regular meetings to discuss and refine the analysis, consider alternative interpretations, and reflect on own positions as researchers, educators, clinicians, and learners. In addition to investigator triangulation, we used an audit trail to enhance the rigor of the analysis.

\section{Results}

We conducted 5 focus group interviews involving 20 participants (average of 4 per interview) between February 2016 and May 2018. Interviews ranged from 18 to 34 (average 27) $\mathrm{min}$.

Junior trainee interviews revealed an educational emphasis on the development and mastery of the knowledge required for EM practice. They discuss simulation as a learning tool useful to develop content expertise. 
"[It's] important to get back to my main objectives: identification of these illnesses and the management." [FG\#1, Jr. Resident].

Their level of comfort during a simulation scenario impacts their view of the benefits of the simulation. Their comfort relates to their familiarity with the knowledge required for the scenario. Conversely, they feel overwhelmed when the scenario pushes the limits of their knowledge.

“... it was sort of overwhelming from a junior perspective to...get a grasp on your [Advanced Cardiac Life Support] algorithm...then also to have to know something more complex [like] the management of [Tricyclic Antidepressants] overdose" [FG\#3, Jr. resident].

They express significant frustration when a simulation scenario requires knowledge that they do not possess. As natural progression through the scenario is stalled by knowledge gaps, they lose faith in the educational value of the exercise. In such cases, learners feel unsupported during the scenario.

"I don't know if that was useful for us to run through [the] simulation because we just didn't know the material...I probably would just have a discussion [rather than] running [a scenario] when we don't know" [FG\#1, Jr. resident].

They fear that their hesitations to act when not knowing may be viewed as a lack of competence by their peers and faculty facilitators.

"[Being team leader] is...big for me... because I feel you're just going to look really stupid...you're like... I don't know... do I give charcoal? I don't know. Do we give sodium bicarb? I don't know." [FG\#1, Jr. resident].

To alleviate the frustration around their lack of knowledge, junior residents suggest being primed with reading materials or with the session-specific learning objectives:

“... my sense is that they're supposed to be a sort of secret for some reason... like we're not supposed to tell other people the cases... but I just think I'm not quite there yet. [I would have preferred] if we had talked about aspirin or had a handout"[FG\#1, Jr. resident].

In contrast, senior trainees appear motivated by learningoriented goals. They focus on developing competencies and on mastering new skills in the simulation environment by finding ways to adapt to new challenges. They enjoy unexpected difficulties and surprises, as they believe that the unpredictability of simulation mimics real-life EM practice. Senior trainees display confidence in their skills during simulation and are more willing to take risks. They expect chaos and feel comfortable making mistakes during the simulation sessions.

"I think I like being surprised; either way is good because that is real life." [FG\#4, Sr. resident].

"I went [to a simulation] one year and it was...stressful...because there was so much going on...there were so many people everywhere...it was chaos. It was great!” [FG\#4, Sr. resident].

Senior trainees perceive simulation as a tool for formative assessment, and an opportunity to reflect on their own performance.

"I don't prepare for the simulation sessions in any way.... I usually use it as a way to just wing it and test myself on the fly to see where I'm at." [FG\#4, Sr. resident].

Rather than focusing on knowledge content, senior trainees express the need to hone their crisis resource management skills through challenging, complex simulation experiences.

"[Simulation] is really just about putting together the ability to be on a team or to lead a team." [FG\#4, Sr. resident].

Not all junior residents and senior residents emulated their colleagues' sentiments with respect to goal orientation. One junior resident expressed comfort with making mistakes and an orientation toward learning. Another senior resident describes feeling the need to perform during simulation.

"I would worry that we would lose the autonomy of being able to make mistakes. We make the mistakes. That's how we learn right?" [FG\#1, Jr resident].

"[During simulation scenarios,] staff are here watching you, so it ups the ante a little bit." [FG\#4, Sr. resident].

Despite these noticeable divergences, senior and junior trainees share similar perceptions about the utility of simulation. For both, it is felt to provide opportunities for exercising autonomy and leadership in a safe environment, skills that are important for their daily clinical practice.

"I think being the leader is something we're all going to do primarily mostly, but it's important to feel a little bit of stress with it, important to start learning to ask for help....It's an important part of the simulation experience." [FG\#5, Jr. resident].

Residents held very specific views on the role of interprofessional learning in simulation. Residents valued observing experts in their professional roles as it allowed residents to gain insight into others' scope of practice and improved interprofessional collaboration skills. However, they believe there to be little benefit when they themselves were asked to 
act as another health care professional, stating that enacting other roles prevents full immersion in the simulation learning experience.

"We all [have] a similar point of view as residents and the training we've had...other health professionals have their own perspectives and training which... I've found incredibly helpful" [FG\#2, junior resident].

"Adding an interprofessional team [to simulation] adds the extra skill of learning to work with interprofessionals" [FG\#4, senior resident].

"I do find when I'm playing an RN or an RT that I'm spending a lot of time fiddling [e.g.] figuring what label is on what drug and [looking for] stuff" [FG \#3, junior resident].

We highlight differences between junior and senior residents' likes or dislikes about the simulation sessions; however, all residents generally view the sessions as beneficial to their learning. For a detailed description of major and minor themes see Table 1 .

\section{Discussion}

Our study illustrates that junior and senior EM participants approach simulation-based training from different perspectives. Junior trainees largely report performance-oriented objectives while senior trainees primarily report learningoriented objectives. Junior trainees are concerned about their knowledge and ability to perform well during simulations. They prefer having prior knowledge of content required for successful management of the case. Senior trainees prefer scenarios where their clinical skills are challenged so that they can reflect on their performance and identify areas for further learning and improvement. They are confident in their skills, feel comfortable making mistakes and enjoy being immersed in chaotic environments. Inter-individual differences did occur within each level of training. This may reflect that goal-orientation is not a personality trait but rather a socially-developed approach to learning. The design of simulation exercises may meet the needs of each learner differently and thus those with varying knowledgebases or comfort-levels may have differing goal orientation.

Junior and senior residents have similar views regarding interprofessional involvement. They value inclusion of actual interprofessionals rather than play acting various roles to maximize authenticity and perceived benefit.

A paucity of studies focuses on gaining a deeper understanding of residents' perspectives on simulation experiences. Although multiple reports of learner satisfaction with simulation-based training exist, very few explore why trainees like or dislike simulation as a learning tool [13]. We were unable to identify studies specifically addressing learner goal orientation during simulation training. However, the broader literature on goal orientation can inform learner-centred simulation-based curriculum design. A learning-goal orientation has been defined as the desire "to develop competence by acquiring new skills and mastering new situations', whereas a performance-goal orientation has been defined as the desire 'to demonstrate and validate the adequacy of one's competence by seeking favourable judgments and avoiding negative judgements about one's competence' [14]. How an individual learner perceives their clinical abilities and chooses to invest efforts in a task is impacted by their goal orientation. With a learning-goal orientation, the learner views their ability as modifiable with dedicated efforts. With a performance-goal orientation, the learner views their ability as fixed and stagnant. Effort is perceived as an indicator of lack of ability, poor performance, and wasted energy unlikely to result in success. In our study, senior trainees and junior trainees report differing goal orientations, impacting their view of the simulation experience.

Importantly, some literature suggests learners may be limited in their ability to accurately predict what is best for their learning [15]. In fact experiencing a level of stress during a learning experience may promote learning rather than hinder it [16]. Goal-orientation matters as it seems to influence a learners' perception around self-efficacy, ongoing investment of efforts during the simulation and receptivity to feedback. If a learner is not engaged, motivated to learn and does not consider an experience useful, they may be dismissive of learning points. In our study, learners who found the simulation session threatening assessed it as less useful which can impact learning.

Our results suggest several impacts of learner goalorientation on simulation curricula design. First, trainees' discomfort and frustration during a simulation session may lead to an inability to accept feedback and address learning gaps. Second, learning experiences should ideally allow the learner to connect prior to new knowledge; a lack of prior knowledge may not provide adequate foundation on which to progressively build learning. In developing simulationbased curricula, educators should consider incorporating preparatory materials for junior learners. Like the flipped classroom educational approach, a flipped simulation session could rely on self-study of knowledge content, followed by simulation-based practice. This may serve to improve trainees' comfort during simulation and increase receptivity to post-scenario feedback. We believe learners should have a minimum foundation of knowledge about the simulation in order to function effectively. Foundational knowledge should be enough to allow the learner to execute decisions and tasks in a manner that facilitates progression of the scenario. If basic knowledge does not exist, the simulation stalls and there is little to no utility in the exercise. For simulation educators with concerns about providing preparatory materials, 
Table 1 Major and minor themes

\begin{tabular}{lll}
\hline Theme & Subtheme & Illustrative quote
\end{tabular}

Major themes

Portraying different goal orientations

Appreciating the utility (or not) of simulation
Developing key knowledge prior to and during "I ended up learning quite a bit about [Tricyclic simulations

Feeling at ease (or not) with not knowing / the unexpected

Antidepressants] overdose in that case but it was sort of overwhelming from a junior perspective to just sort of get a grasp on your ACLS algorithm but then also to have to know something more complex in terms of the management of Tricyclic Antidepressants] overdose" [FG\#3, Jr. resident]

"So I think it's very topic dependent... our comfort level with the material has to be at a certain level for [the simulation] to be beneficial...we actually knew the management of asthma... in a less severe case, we knew the treatments and we knew what we were doing. We knew how to start the process." [FG\#1, Jr. resident]

"I think I like being surprised; either way is good because that is real life. It's always good to keep a sort of wide differential in your mind." [FG\#4, Sr. resident]

"I went [to a simulation] one year and it was like, oh this is actually stressful right now, you know, because there was so much going on and there were so many people everywhere and it was chaos. It was great!" [FG\#4, Sr. resident]

"I don't know, you just feel like it's okay to be wrong about this stuff and it's okay to be like, guys, I don't know how to manage this, what do you guys think?" [FG\#2, Sr. resident

"[Being team leader] is just big for me personally because I feel you're just going to look really stupid because half the time you're like... I don't know... do I give charcoal? I don't know. Do we give sodium bicarb? I don't know. Do we replace potassium? I don't know." [FG\#1, Jr. resident]

"Oh yeah, how do I actually do that-and then you realize you have a gap in putting [positive end-expiratory pressure] valves on a human being or something that you might not have realized. So I think there's some useful or some utility in like going through it live with a scenario" [FG4, Sr resident]

"Trach care but then realistically it was no, just like pull everything out and just intubate through the nose and that's sort of like an absolute airway disaster case that you might never come to, but you really want to know that sort of stuff, like that was really useful.’[FG\#\$, Sr resident]

"I don't know if that was useful for us to run through [the] simulation because we just didn't know the material...I think in terms of efficiency, for me, I probably would just have a discussion [rather than] running [a scenario] when we don't know" [FG\#1, Jr. resident] 
Table 1 (continued)

Theme Subtheme

Subtheme

Illustrative quote

Exercising autonomy and leadership

Integrating interprofessionality into simulation

Integrating interprofessionality into simulation

Minor themes

Benefiting from Peer Learning
Role playing other professional roles during simulation

Finding value in interprofessional simulations
"Simulation gives you a chance to be in a position where you have to communicate or even make decisions. Even if the decisions to be made [are low-stakes], you still have your colleagues looking at you to make decisions." [FG\#4, Sr. resident]

"There's the rest of our curriculum [focused on] our actual medical knowledge... but [simulation] is really just about putting together the ability to be on a team or to lead a team." [FG\#4, Sr. resident]

"I think being the leader is something we're all going to do primarily mostly, but it's important to feel a little bit of stress with it, important to start learning to ask for help because you're still going to do that in the real world. So I think it's an important part of the simulation experience." [FG\#5, Jr. resident]

"We can learn by bouncing ideas off of each other but we also don't necessarily know what an RT would do in that situation, so it can be nice having them there" [FG\#4, Sr resident]

"The sims I remember with interprofessional staff, I feel like they just know so much of what they're doing that things go

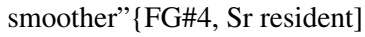

"Its less helpful [for] a resident to act as a nurse because that takes away from the role you'll be fulfilling in the real world [and] you are going to gain less" [FG\#2, junior resident]

"I do find when I' $m$ playing an RN or an RT that I'm spending a lot of time fiddling with sim crap like figuring what label is on what drug and [looking for] stuff" [FG \#3, junior resident]

"Okay, I just got asked to do all of these orders and I already forget which the first one is", so you sort of learn to be a better team leader by being on the other side in some ways right, “ [FG\#4, Sr resident]

"I think we all come in many ways with a similar point of view as residents and the training we've had....and...other health professionals have their own view from their perspectives and training which...in the real world I've found incredibly helpful" [FG\#2, junior resident]

"Adding an inter-profesional team [to simulation] adds the extra skill of learning to work with inter-professionals and so if that's one of the objectives it makes sense" [FG\#4, senior resident]

"Its just interesting to see how different people have different perspectives on how they would've...individually [make decisions]" [FG\#2, junior resident] 
Table 1 (continued)

\begin{tabular}{|c|c|c|}
\hline Theme & Subtheme & Illustrative quote \\
\hline & & $\begin{array}{l}\text { "I think there's a lot of value in the fact that we } \\
\text { are all in there together in.... a safe environ- } \\
\text { ment learning with each other and can help } \\
\text { each other...just talking through the scenario" } \\
\text { [FG\#3, junior resident] }\end{array}$ \\
\hline & & $\begin{array}{l}\text { "Hopefully in our program people feel sup- } \\
\text { ported by the seniors... and the juniors are } \\
\text { able to use some of their [seniors knowledge- } \\
\text { base] in running the sims" [FG\#5, senior } \\
\text { resident] }\end{array}$ \\
\hline \multirow[t]{3}{*}{ Fidelity impacting educational value } & & $\begin{array}{l}\text { "The stuff I found frustrating is the stuff that } \\
\text { you can't get from the manikins" [FG\#3, } \\
\text { Junior resident] }\end{array}$ \\
\hline & & $\begin{array}{l}\text { "It's hard to simulate a lot of the decision or the } \\
\text { features that would lead us to make that final } \\
\text { decision.to actually pull the trigger on intuba- } \\
\text { tion" [FG\#2, Junior resident] }\end{array}$ \\
\hline & & $\begin{array}{l}\text { "I think part of [disaster day simulation] } \\
\text { was the real life actors and that...there was } \\
\text { more volume, so you are being dragged in } \\
\text { different directions every two minutes so its } \\
\text { more stressful like real life" [FG \#4, Senior } \\
\text { resident] }\end{array}$ \\
\hline \multirow[t]{3}{*}{ Debriefing as a key component for learning } & & $\begin{array}{l}\text { "I usually find more value in the debriefing ses- } \\
\text { sions than the sim at this level" [FG\#1, junior } \\
\text { resident] }\end{array}$ \\
\hline & & $\begin{array}{l}\text { "We get a lot of feedback at the end, we talk } \\
\text { about the case, the correct dosages... and } \\
\text { that's great... and I would like to spin it } \\
\text { around and say what if it was a patient with } \\
\text { adrenal suppression... how would you manage } \\
\text { a person like that?" [FG \#3, junior resident] }\end{array}$ \\
\hline & & $\begin{array}{l}\text { "I think there's also impact from watching your- } \\
\text { self [on a video] and seeing how you actually } \\
\text { performed...this may help you perform [bet- } \\
\text { ter] later on.” FG\#2,junior resident] }\end{array}$ \\
\hline
\end{tabular}

simulation scenarios could better match trainees' clinical exposure by ensuring that early sessions focus on common problems encountered early and frequently during clinical training. For senior trainees desiring more challenging scenarios focusing on crisis resource management skills, educators could incorporate interprofessional and other challenges related to physical fidelity, as both would better reproduce the dynamic, team-based, noisy environment of the ED. Objectives of a session should reflect a focus on improving interprofessional communication if other professional roles are to be included. One notable challenge is the complexity of replicating the chaos and unpredictability of the ED in a simulated environment. Even the most astute simulationist may find this task particularly difficult within the confines of space, time, budget and personnel limitations. Finally, to further satisfy learning-goal orientation during the debrief, facilitators may focus more on aspects of communication and decision-making for senior residents, and more on filling in knowledge gaps for junior residents. Expert debriefers draw on their debriefing skills to expose the choices and actions of learners during the simulation in order to weave in objectives effectively promoting long term learning [17]. Such variations in educational approaches for junior and senior trainees assume separate curricula for both groups of trainees.

\section{Limitations}

Participants' first impressions, immediately after a simulation session, may lack the insight gained after deliberate reflection or over years of training, although the interview 
guide sought opinions on both current and past simulation sessions. In addition, participants may have participated in the interview half-heartedly, eager to leave. A few residents did not remain for the interviews (approximately $1 /$ session) as such our findings may not reflect all opinions. Both factors may have limited the scope and depth of our findings. Two peers of the study participants conducted interviews in order to create a safe environment so that participants felt comfortable commenting about the simulation training. The interviewers were trained but had limited experience in qualitative interviewing. Participants may have chosen not to share their views on the simulation curriculum in front of their peers in fear of judgement.

\section{Future directions}

An area for future exploration would be whether junior residents move from performance-goal orientation to learninggoal orientation as they progress through their training. Is their goal orientation fixed or stagnant? If orientation changes over time, what factors contribute to this change. The authors suggest that these questions could be answered through further qualitative research.

\section{Conclusion}

Junior and senior EM residents at our institution differ in their goal orientation during simulation-based training. Educators who develop simulation-based curricula should be mindful of these differences when designing simulation sessions targeted towards learners with different levels of training and clinical experience.

Supplementary Information The online version contains supplementary material available at https://doi.org/10.1007/s43678-021-00085-z.

\section{Compliance with ethical standards}

Conflict of interest The authors declare no conflict of interest.

\section{References}

1. James T, Nadel ES, Bhatia K, Walls RM. Incorporating simulation into a residency curriculum. CJEM. 2010;12(4):349-53.

2. McKendy KM, Posel N, Fleiszer DM, Vassiliou MC. Learnercreated virtual patient curriculum for surgical residents successes and failures. J Surg Educ. 2016;73(4):559-66.

3. Mathai SK, Miloslavsky EM, Contreras-Valdes FM, MiloshZinkus T, Hayden EM, Gordon JA, et al. How we implemented a resident-led medical simulation curriculum in a large internal medicine residency program. Med Teach. 2014;36(4):279-83.

4. Brackenbury T. A qualitative examination of connections between learner-centered teaching and past significant learning experiences. JoSoTL. 2012;12(4):12-28.

5. Nunninl L, Thompson A. Peer-assisted learning in scenario-based simulation. Med Ed. 2018;52(5):557-8.

6. Cook DA, Hamstra SJ, Brydges R, Zendejas B, Szostek JH, Wang AT, et al. Comparative effectiveness of instructional design features in simulation-based education: systematic review and metaanalysis. Med Teach. 2013;35(1):867-98.

7. Mundell WC, Kennedy CC, Szostek JH, Cook DA. Simulation technology for resuscitation training: a systematic review and meta-analysis. Resuscitation. 2013;84(9):1174-83.

8. Bunniss S, Kelly DR. Research paradigms in medical education research. Med Educ. 2010;44(4):358-66.

9. Stalmeijer RE, McNaughton N, Van Mook WN. Using focus groups in medical education research: AMEE Guide No. 91. Med teach. 2014;36(11):923-39.

10. Royal College of Physicians and Surgeons of Canada. Objectives of Training in the Specialty of Emergency Medicine. Ottawa: Royal College of Physicians and Surgeons of Canada; 2014.

11. Saunders B, Sim J, Kingstone T, Baker S, Waterfield J, Bartlam B, et al. Saturation in qualitative research: exploring its conceptualization and operationalization. Qual Quant. 2018;52(4):1893-907.

12. Charmaz K. Constructing grounded theory: A practical guide through qualitative analysis. London: SAGE Publications; 2006.

13. Schieman C, Ujiie H, Donahoe L, Hanna W, Malthaner R, Tumer S, et al. Developing a national simulation-based surgical skills boot camp in general thoracic surgery. J of Surg Educ. 2018;75(4):1106-12.

14. VandWalle D, Cummings L. A test of the influence of goal orientation on the feedback-seeking process. J Appl Psychol. 1997;82(3):390-400.

15. Sargeant J, Eva KW, Armson H, Chesluk B, Dornan T, Holmboe $\mathrm{E}$, et al. Features of assessment learners use to make informed selfassessments of clinical performance. Med Ed. 2011;45:636-47.

16. Rudland JR, Clinton G, Wilkinson TJ. The stress paradox: how stress can be good for learning. Med Ed. 2020;54(1):40-5.

17. Fanning RM, Gaba DM. The role of debriefing in simulationbased learning. Simul Healthc. 2007;2(2):115-25. 